\title{
La maternidad en conflicto en The Gathering de Anne Enright y La hija oscura de Elena Ferrante
}

\section{Resumen}

Este trabajo se propone revisar las representaciones sobre la maternidad en dos novelas de autoras contemporáneas, The Gathering, de la irlandesa Anne Enright y La hija oscura, de la italiana Elena Ferrante. La necesidad de rebatir y debatir los discursos patriarcales sobre la maternidad no es patrimonio único de las intelectuales feministas de los siglos XX yXX, sino que es evidente en la obra de muchas escritoras. En este trabajo se busca indagar los vínculos entre la construcción de la maternidad como relación social y la literatura, en tanto espacio de confluencia de diversos discursos sociales que se resignifican en los diferentes campos en los que circulan. Este trabajo no pretende ser exhaustivo, sino una reflexión sobre las relaciones entre narrativa y maternidad en las obras citadas, dejando abierto el camino para que se amplíe el corpus por analizar en un futuro.

Palabras clave: maternidad; feminismo; novela contemporánea; literatura comparada.

Conflict motherhood in Anne Enright's The Gathering and Elena Ferrante's Lost Daughter

\begin{abstract}
This paper intends to review the representations of motherhood in two novels by contemporary authors, The Gathering by the Irish Anne Enright and The Lost Daughter by the Italian writer, Elena Ferrante. The need to refute and debate patriarchal discourses on motherhood is not the sole heritage of feminist intellectuals of the twentieth and twenty-first century, but it becomes evident in the work of different writers. This paper seeks to investigate some of the links
\end{abstract}


between the construction of motherhood as a social relationship and literature, as a space of confluence of various social discourses that are resignified in the different fields in which they circulate. This work is not intended to be exhaustive but a reflection on the relationship between narrative and motherhood in the works cited, paving the way for a potential corpus to be analyzed in the future.

Keywords: motherhood; feminism; contemporary novel; comparative literature.

\section{Literatura, feminismo y maternidad}

En las últimas décadas, el pensamiento feminista ha retomado el tema de la maternidad de forma compleja y profunda. El feminismo ha dado cuenta de la naturaleza construida del género desde hace tiempo, tal conciencia apuntala y alimenta los debates actuales sobre la maternidad. Desde que Adrienne Rich (1986) distinguió entre motherhood (maternidad), una institución patriarcal, y mothering ${ }^{1}$ entendida como la relación de la mujer con su capacidad de reproducción y los hijos, se han desarrollado una gran cantidad de teorías feministas sobre la maternidad. La maternidad no es vista como un estado fijo, estático sino como ideas y comportamientos mutables, contextuales. Hablar de mothering es acentuar la naturaleza activa de la maternidad en amplio contraste con una visión tradicional patriarcal de nuestra cultura que ve a la madre como pasiva y sin poder. También sienta las bases para entender la conducta de las madres como performativa y potencialmente subversiva (Butler, 2016).

El pensamiento más reciente sobre la maternidad se encuentra en el trabajo de Judith Butler, quien concibe el género como una serie de actos performativos. A la luz de esta teoría, la maternidad es una práctica y la subjetividad maternal no es estática sino un proceso, construido constantemente o "performado". Se debería, entonces, hablar de "subjetividades maternales". Esta idea ha sido central al feminismo postmodernista que resalta la diversidad y la multiplicidad. Las actitudes maternales contienen el potencial de una disrupción de los discursos dominantes patriarcales sobre la maternidad, que dependen de su actuación (performance) para ser válidos y que, por lo tanto, son vulnerables, abiertos a cambio. Entender mothering de esta manera es hacer lugar a la idea de una agencia maternal (Hansen, 1997).

La ficción más reciente ha tratado de recuperar la voz de la madre. Las escritoras de las postrimerías del siglo XX han revisado los mitos maternales para expresar las peculiaridades de la búsqueda femenina. En algunas autoras del siglo XX (Margaret Atwood, Marguerite Duras, Christa Wolf, Toni Morrison, Alice Walker, entre otras) la madre comienza a aparecer en las novelas como sujeto. Al hacerse audible en la literatura la voz maternal tan censurada y silenciada previamente, los textos ficcionales ayudan a los estudios y a la crítica de esa maternidad.

1 "Mothering" dentro de la teoría de la maternidad no significa exclusivamente saber desarrollar el papel de madre, sino cuidar de los demás en un sentido más amplio." (La traducción es mía). Jeremiah, E. (2006) (pp. 21-33) 
La inclusión de la literatura escrita por mujeres es parte de la revisión del canon literario occidental que ha sido mayormente androcéntrico. Se aboga por las tradiciones centradas en mujeres, la teorización sobre formas de escritura decididamente femenina y la consideración, no sólo del género, sino de la etnicidad, clase, religión y sexualidad de los autores y los protagonistas al valorar el contenido cultural y estético de los textos.

Los textos literarios construyen diversas representaciones de la maternidad de acuerdo a normas genéricas, procedimientos narrativos y/o estrategias textuales; participan del constructo social interpretativo de la maternidad, se aproximan y discrepan con otros discursos sociales contemporáneos. La omisión de la madre en los constructos teóricos o bien su ausencia en el orden simbólico demuestran que la cultura patriarcal los ha reprimido en todos los planos excepto en la idealización o romantización. (Domínguez, 2007).

La aparición de la madre como personaje principal y la cuestión de la maternidad, un argumento que también aborda la dimensión de las relaciones, especialmente madre-hija, comienzan a tener una mayor visibilidad a partir de mediados del siglo XX, coincidiendo con el auge de la visibilidad de las escritoras.

La narrativa le ofrece a la maternidad un esquema, la coloca en un relato y le da temporalidad y sujetos (madres e hijos), le destina un lugar, aunque sea móvil o temporal (el espacio privado). El espacio literario permite la transgresión bien como latencia o como marginalidad. La maternidad, en general, está marcada por mandatos y regulaciones; su contacto con la literatura la libera de formas estereotipadas y la prepara para ser transgresora (Domínguez, 2007).

Las dos obras que se analizan en este trabajo cuestionan la maternidad, mostrando la lucha individual de las mujeres en su esfuerzo por negociar una identidad. La maternidad no aparece como un guión determinado por la biología, sino más bien como un deseo que puede responder o no al mandato social. Tanto la escritora irlandesa Anne Enright, como la italiana Elena Ferrante han consolidado una mirada de mujer en sus narrativas mediante retratos íntimos de mujeres en su vida familiar, doméstica y privada.

La figura de la madre en la historia social y cultural de Irlanda es considerada uno de los mitos que ayudó a construir la identidad nacional del país. La Iglesia Católica fue una de las instituciones regulatorias más importantes en la construcción ideológica nacional y la idealización de la mujer deriva, especialmente, de la analogía entre la madre irlandesa y la Virgen María, virgen-madre. Desde el Estado y también desde la Iglesia se construye el símbolo de la maternidad como sagrada. En Irlanda, la institución familiar es de especial importancia y el Estado ha hecho un esfuerzo considerable para protegerla y asegurar el rol de la mujer de esa manera a fin de mantener ese modelo ideal de sociedad. La Constitución de Irlanda de 1937, por ejemplo, distingue formalmente a los hombres de las mujeres al reconocer el rol de las mujeres en la esfera privada 
como amas de casa, esposas y, mayormente, madres: "In particular, the State recognises that by her life within the home, woman gives to the State a support without which the common good cannot be achieved" (Constitution of Ireland, Art. $\left.41.21^{\circ}\right)^{2}$

La aparición general del feminismo hizo que la situación de las mujeres fuera cambiando lentamente. La cantidad de mujeres escritoras y artistas que se hicieron públicas creció significativamente, se establecieron editoriales feministas y se implementaron programas de Estudios de Mujeres en diversas universidades. Esta revolución silenciosa culminó con la elección de Mary Robinson como la primera mujer presidente en Irlanda en 1990. No será sino hasta el nuevo siglo que van a darse a conocer las numerosas atrocidades cometidas principalmente entre los años 1930 y 1980 contra muchas mujeres en Irlanda. ${ }^{3}$ Si bien la vida de las mujeres ha mejorado de diversas maneras todavía queda trabajo por hacer, considerando que las mujeres siguen poco representadas tanto en la política como en los negocios. El hecho de que las mujeres rara vez ocupen puestos de influencia puede atribuirse, en parte, a la falta de guarderías y otros servicios para padres que trabajan fuera del hogar.

En la Italia de principio del siglo XX, las funciones de mothering se combinaron en una sola figura: la de la madre que da luz, cría y educa a sus hijos en el hogar. Este fenómeno no se limitó a Italia (como se comentó anteriormente en el caso de Irlanda) y puede atribuirse a una variedad de factores económicos, sociales y culturales. A medida que la Revolución Industrial separaba el hogar del lugar de trabajo, las madres se asociaban cada vez más, en teoría, si no siempre en la práctica, con la esfera doméstica. El modelo detrás de esta representación de la madre abnegada y poderosa es claramente religioso, al igual que en Irlanda. El culto a la Virgen-madre se había renovado poderosamente en la segunda mitad del siglo XIX. El dogma de la Inmaculada Concepción (es decir, que María nació sin la "mancha" del pecado original que la humanidad carga desde Adán y Eva) fue proclamado en la bula Ineffabilis Deus el 8 de diciembre de 1854. La Italia de posguerra también estuvo marcada por un nuevo impulso al culto de la Virgen María, en línea con el énfasis puesto por el Papa Pío XII en la "madre cristiana" como "la verdadera fuerza y el orgullo de Italia" (Benedetti, 2007). En 1925, se funda la ONMI (Opera nazionale maternità ed infancia) que atendió a madres e hijos que vivían fuera de la estructura familiar tradicional. A diferencia de lo sucedido en Irlanda, las mujeres solteras recibieron atención médica gratuita y una compensación financiera durante el último trimestre de su embarazo. En algunos casos, se les permitió residir en instituciones especiales (Case della Madre e del Bambino). A partir de 1934, las mujeres trabajadoras lograron dos meses de licencia de maternidad pagada. Si bien estas medidas parecen haber sido diseñadas

2 "En particular, el Estado reconoce que, con su vida dentro del hogar, la mujer brinda al Estado un apoyo sin el cual no se podría conseguir el bien común." (Constitución de Irlanda, Art. 41. 2 1ํ) (La traducción es mía).

3 Nos referimos principalmente a la práctica indiscriminada de sinfisiotomías en hospitales públicos irlandeses: el confinamiento de mujeres embarazadas fuera del matrimonio en las infames "Magdalene Home Laundries" donde hacían trabajo casi esclavo, para luego quitarles los hijos y darlos en adopción. Estas mujeres por lo general morían en la extrema pobreza; para ellas resultó muy tardía la ley de aborto (Brogan, 2004). 
para ayudar a las mujeres a equilibrar las responsabilidades del trabajo y la familia, otras iniciativas dejaron en claro que su objetivo final era limitar a las mujeres a la esfera doméstica.

La introducción del nuevo Código de Familia en 1975 significó un hito porque aseguró mayor igualdad entre los sexos en el matrimonio, así como en relación con los hijos. Sin embargo, no fue hasta 1981 que las leyes relativas al "delitto d'onore" (que consideraban el asesinato como respuesta legítima al adulterio) y al "matrimonio riparatore" (que otorgaba impunidad a los violadores que se casaban con sus víctimas) fueran derogadas. Finalmente, en 1996, terminando un debate que había durado diecisiete años, el parlamento logró superar sus divisiones y aprobó una ley que cambió la normativa en lo referente a la violencia sexual (Benedetti, 2007).

En el período comprendido entre los años 1981-2004 se palparon las consecuencias de la constante y aparentemente imparable disminución de la tasa de natalidad. Si bien el fenómeno no se limitó al ámbito italiano, esa tendencia alcanzó proporciones únicas en la península y se acusó al feminismo de distraer a las mujeres de su verdadera misión. A pesar de algunas iniciativas adoptadas en apoyo de las familias (como la extensión de beneficios parentales para los padres), la tendencia ha continuado hasta muy recientemente y, en 1998 la tasa de natalidad llegó a 1,19 hijos por año, una de las más bajas del mundo. Italia es hoy en día el país con la población más anciana de Europa, sólo una ola de inmigración (fenómeno sin precedentes para un país de emigrantes) parece haber evitado que la situación se volviera catastrófica.

Anne Enright, nacida en Dublín en 1962, es considerada como una de las escritoras más talentosas de la nueva escena irlandesa. Ha recibído varios premios, entre ellos, el prestigioso Man Booker Prize (2007) por la novela The Gathering. Su producción literaria abarca varios géneros: ha publicado novelas, no-ficción y tres colecciones de cuentos.

Enright construye su narrativa a través de la conciencia de los protagonistas cuyos sentimientos, esperanza y memoria son el tema principal de la narración. De esta manera lo innovador de su trabajo resulta de la diferencia entre la realidad de los protagonistas y la imagen ideal de la madre/esposa/hija que se presenta en diversos discursos de la sociedad irlandesa, de neto corte patriarcal.

The Gathering fue publicada en $2007^{4}$, es la cuarta novela de Enright y la que la lanza a la popularidad. Esta novela se propone investigar el cambio social silenciado en la historiografía pública de Irlanda, especialmente la identidad femenina. Enright rastrea tres generaciones de mujeres Hegarty desde la Independencia (1921) hasta el Tigre Celta ${ }^{5}$ con el fin de visualizar la arqueología de la maternidad en Irlanda.

4 Se publica en español como El encuentro con traducción de Francisco Javier Calzada para la editorial Lumen, Barcelona, 2009.

5 Tigre Celta (Celtic Tiger): Período de economía floreciente de Irlanda entre 1990 y 2000. 
La enigmática escritora italiana Elena Ferrante ha revolucionado el panorama literario contemporáneo con su ficción realista centrada, principalmente, en el universo femenino. Igualmente popular es el hecho que poco (o nada) se sabe de su vida, es más, hay críticos que han dudado de su existencia si bien se especula que nació en Nápoles en 1943.

Elena Ferrante empezó a publicar en los años noventa, pero recién con la publicación de L'amica geniale (2011), la primera entrega de la llamada tetralogía napolitana, saltó al escenario internacional. Anteriormente, había publicado L'amore molesto (1992), I giorni dell'abbandono (2002), y La figlia scura,(2006). En 2012 sale Cronache del mal d'amore donde se recopilan las tres novelas anteriores. Todas las novelas de Ferrante han sido traducidas al español.

La figlia scura (2006) se publica en español en 2015 como La hija oscura en la recopilación Crónicas del desamor que incluye El amor molesto y Los días del abandono.

Elena Ferrante ganó varios premios: el "Procida-Isola di Arturo-Elsa Morante" (1992), el premio Oplonti de plata, fue candidata al Premio Strega, máximo galardón en Italia, y ha sido largamente elogiada por la crítica literaria internacional. En su narrativa, Ferrante explora aspectos de la experiencia femenina (maternidad, amistad, femineidad, sexualidad) a través de la conciencia de los personajes, quienes intentan ahondar en sus problemas y re-encaminar sus vidas. En su mayoría, son mujeres que sufren fuertes desequilibrios emocionales y comienzan un dificultoso camino hacia la reconstrucción personal, cuestionando los roles femeninos y los diferentes vínculos que se crean entre mujeres.

\section{The Gathering/El Encuentro-Anne Enright ${ }^{6}$}

La protagonista de The Gathering, Veronica Hegarty, es una mujer de treinta y tantos años, de clase media, ama de casa y madre. Verónica es la octava de doce hijos y, al comienzo de la novela, está en camino a la casa materna para comunicarle a su anciana madre que Liam, el hijo rebelde de esta, acaba de suicidarse. Verónica vuelve al pasado para tratar de encontrar una respuesta sobre qué estuvo mal en la vida de su hermano Liam para llevarlo a cometer semejante acto. Al buscar respuestas en el pasado, indaga en la historia familiar y lucha por escribir la verdadera historia de su familia: "this is the tale that I would love to write: history is such a romantic place [...] If it would just stay still, I think, and settle down. If it would just stop sliding around in my head"7 (Enright, 2007: 13).

6 N.B.: Para las citas en idioma inglés se usará la edición: Enright, A. (2007) The Gathering London: Vintage; para las citas en español se usará la edición: Enright, A. (2009) El encuentro. Barcelona: Lumen. 
La condicionalidad de la declaración de Verónica sobre la historia sugiere que resultaría mucho más fácil escribir el pasado como un lugar "romántico", sin embargo, a fin de romper el silencio de una narrativa patriarcal opresiva, debe "reescribirlo". Verónica es una mujer de la "nueva Irlanda"; a través de ella, Enright critica la incapacidad de las mujeres irlandesas modernas para reconstituir una identidad en medio de un pasado patriarcal poco confiable. Al borde de la invisibilidad, Verónica, impulsada por el suicidio de su hermano, se adentra en su propio pasado para (re)escribir su historia, y al hacerlo expone los factores políticos, sociales y familiares cómplices en el silenciamiento de la feminidad irlandesa, reclamando su subjetividad.

Verónica busca respuestas en el pasado y demuestra la conexión entre los miembros de la familia y la comunidad además de destacar cómo una vida afecta crucialmente a otra. Enright lo plantea desde el comienzo de la novela:

I would like to write down what happened in my grandmother's house the summer I was eight or nine, but I am not sure if it really did happen. I need to bear witness to an uncertain event (Enright, 2007: 1) $)^{8}$

La muerte de Liam le muestra que "I have lost something that cannot be replaced" (Enright, 2007: 11) y que, para contar la historia de esa pérdida, "I have to start long before he was born" (Enright, 2007: 13). ${ }^{9}$ Verónica comienza esta investigación recreando la historia de cómo el abusador de su hermano, Lamb Nugent, entró por primera vez en sus vidas al enamorarse de su abuela, Ada Merriman. Veronica no revela la naturaleza del "evento" que habrá de cambiar la vida de su hermano hasta bien adelantada la narración, y confiesa que "it may be a false memory" (Enright, 2007: 144). ${ }^{10} \mathrm{Al}$ buscar el origen del suicidio de su hermano, entonces lo que sucedió (o no) en la casa de la abuela cobra mayor significado, existe un notorio sentimiento de culpa.

Veronica tiene problemas para establecer su historia personal, en parte, porque se da cuenta de que sus recuerdos "verdaderos" resultan ser tan ficticios como los que ella imagina. Veronica se siente culpable de no haber dado testimonio del abuso a su hermano, del cual fue testigo accidental. Sin embargo, el hecho sólo tuvo sentido para ella una vez que los casos de violencia y abuso infantil en Irlanda se hicieron públicos en la década de 1990:

Over the next twenty years, the world around us changed and I remembered Mr. Nugent. But I never would have made that shift on my own - if I hadn't been listening to the radio, and reading the paper, and hearing about what went on in schools and churches and in people's homes. (Enright, 2007: 172-73)."

8 Me gustaría contar qué ocurrió en casa de mi abuela el verano en que yo tenía ocho o nueve años, pero no estoy segura de sí sucedió en realidad. Necesito dar testimonio de un hecho que no sé si es cierto (Enright, 2009: 5).

9 "soy yo quien ha perdido algo irreemplazable" (Enright, 2011: 35) // "tendré que empezar mucho antes de que él naciera" (Enright, 2009: 39)

10 "podría ser un recuerdo falso" (Enright, 2009: 439).

11 Durante los veinte años siguientes el mundo cambió y yo recordé al señor Nugent. Jamás hubiera realizado 
La muerte de Liam le permite a Verónica (re)examinar el pasado de su abuela, Ada (1920, en tiempos de la Independencia), así como su propia niñez y la vida adulta de su madre (década de 1960, anterior al fenómeno Tigre Celta), exponiendo así los prejuicios, prácticas e instituciones que facilitaron tanto la perpetración como la represión de la violencia contra personas vulnerables por el estado irlandés (Sydora, 2013). Las incursiones de Veronica en el pasado se enfocan en Ada y Lambert, no sólo porque el abuso tuvo lugar en la casa de Ada, sino porque ella cree que lo sucedido a Liam es culpa de su abuela que no supo protegerlo. Para Verónica, Ada es el origen de la crisis familiar, cuyos efectos todavía continúan acechando en el presente.

This is the moment for blame. [...] This is the moment when we realise that it was Ada's fault all along. [...] This is the moment when we ask what Ada did [...] to bring so much death into the world (Enright, 2007:223). ${ }^{12}$

Veronica expone la ideología política de la maternidad como una incertidumbre poscolonial que confina a todas las mujeres a una identidad subordinada y doméstica. El cuerpo femenino, entonces, constituye un sitio meramente pasivo para la reproducción donde no cabría la posibilidad de deseo sexual. La noción de asexualidad femenina coincide con la discusión de Julia Kristeva sobre el cristianismo y la maternidad. Según Kristeva, la madre participa en la comunidad simbólica del cristianismo, "no al dar a luz a sus hijos, sino simplemente preparándolos para el bautismo" (Kristeva en Oliver, 1997: 146). La afirmación de Veronica: "everyone wants a bit of me. And it has nothing to do with what I might want, or what my body might want, whatever that might be" (Enright, 2007: $244)^{13}$ bien podría aplicarse a cualquier mujer a lo largo de la historia irlandesa, y de esa manera, ejemplifica las consecuencias violentas de la formación de la identidad nacional en la Irlanda poscolonial. Veronica recuerda "el mantra de su niñez" que corresponde a esa ideología:

Don'ttell Mammy, because 'Mammy' would - what? Expire? Mammy would worry. Which seemed fine to me. It was, after all, of her own making, this family. It had all come - singly and painfully - out of her (Enright, 2007: 9)..$^{14}$

Tanto las relaciones de la abuela Ada como las de la madre de Veronica con sus familias se definen por esta capacidad de proporcionar comodidad doméstica

ese cambio por mí misma... si no hubiera escuchado la radio, leído el periódico y oído contar lo que ocurría en las escuelas, las iglesias y los hogares (Enright, 2009: 526).

$12 \mathrm{Ha}$ llegado el momento de las culpas. [...] Este es el momento en que nos damos cuenta de que todo ha sido culpa de Ada [...] Ha llegado el momento de preguntarse qué hizo Ada — porque sin duda algo debió de hacerpara traer tanta muerte al mundo (Enright, 2009: 675).

13 "Todo el mundo quiere un trozo de mí. Y eso no tiene nada que ver con lo que yo o mi cuerpo podamos querer, sea lo que sea" (Enright, 2009: 736).

14 «No se lo digas a mami», porque «mami» ... ¿qué? ¿Se moriría? No, porque mamá "se preocuparía». Lo que a mí ya me parecía bien. Después de todo, esta familia era su creación. Había salido — de uno en uno y con dolores-de ella (Enright, 2009: 30). 
silenciosa y dedicada, y reproducir patrones estereotipados de domesticidad "cups of tea," "descendants," “money," y "heterosexuals"15 (Enright, 2007: 185-186).

En un momento, Veronica admite su propia complicidad en la perpetuación de la inacción de su madre:

We pity our mothers, what they had to put up with in bed or in the kitchen, and we hate them or we worship them, but we always cry for them - at least I do. The imponderable pain of my mother, against which I have hardened my heart (Enright, 2007: 185). ${ }^{16}$

Sin embargo, la imagen de la femineidad con la cual Verónica "ha endurecido su corazón" es la misma imagen en que ella se ha convertido. Mientras reflexiona sobre su propia historia, refiere irónicamente

better, faster life, the one I have now, cooking for a man who doesn't show up before nine and for two girls who will shortly stop showing up too. Having tearstreaked sex, once in a blue moon, with my middle-aged husband; not knowing whether to hit him or kiss him (Enright, 2007: 82). ${ }^{17}$

El suicidio de Liam le hace confrontar la realidad del pasado y salir del papel de víctima. Veronica señala el fracaso de la maternidad como una ideología dentro de la esfera privada. El hogar, como un espacio de resguardo psicológico y emocional de las ansiedades de la vida moderna, así como amparo físico del mundo exterior hostil, no protege adecuadamente a la familia. Veronica acusa a las figuras maternas por no preservar el hogar y culpa a su propia madre por el abuso que se cometió contra Liam cuando niño y también por su posterior muerte:

I am saying that, the year you sent us away, your dead son was interfered with, when you were not there to comfort or protect him, and that interference was enough to send him on a path that ends in the box downstairs (Enright, 2007: 213). ${ }^{18}$

La incapacidad de proveer un espacio doméstico seguro apunta a una crisis en la maternidad. Sin otro modelo de mujer más que su madre y su abuela, Veronica está condenada a repetir las costumbres de sus predecesoras, condicionada a una versión patriarcal de la maternidad. La protagonista vive en una Irlanda en la que las estructuras sociales tienen mayor liberalización y donde se han

15 "tazas de té", "descendientes", "dinero" y "heterosexuales" (Enright, 2009: 561)

16 Nos compadecemos de nuestra madre, por lo que ha tenido que aguantar en la cama o en la cocina, y la aborrecemos o la veneramos, pero siempre lloramos por ella..., al menos yo. El imponderable dolor de mi madre, contra el que he endurecido mi corazón (Enright, 2009: 558).

17 Una vida mejor y más acelerada, la que llevo ahora, cocinando para un marido que jamás aparece antes de las nueve y para dos niñas que pronto dejarán de aparecer también. Haciendo el amor muy de vez en cuando entre lágrimas con mi marido de mediana edad; sin saber si golpearlo o besarlo (Enright, 2009: 251).

18 Lo que estoy diciendo es que el año que nos enviaste a casa de la abuela abusaron de tu difunto hijo, cuando tú no estabas a su lado para consolarlo o protegerlo, y que ese abuso bastó para mandarlo por la senda que conduce al ataúd (Enright, 2009: 647). 
creado más oportunidades para que las mujeres revalúen y puedan modificar sus roles familiares.

Aunque Veronica culpa a su madre y a su abuela por no proporcionar un modelo de identidad femenina contra-hegemónica, también señala su propio sentido de culpa. La reescritura de la identidad de Veronica comienza cuando ella es capaz de aceptar a su madre y su propio papel como esposa y madre. Ella termina reconociendo que su madre ha sido una víctima:

The past is not a happy place. And the pain of it belongs to her more than it does to me, I think. Who am I to claim it for my own? My poor mother had twelve children (Enright, 2007: 233). ${ }^{19}$

Esta comprensión, si bien no reconcilia a Veronica con su madre, le proporciona impulso para que redefina los parámetros de su propia visión de la maternidad: "I want to find the person that I built from my body's own stuff [...] I want to finish the job of making her, because when she is fully made she will be strong (Enright, 2007: 152). ${ }^{20}$

The Gathering descubre las capas de una historia personal para contribuir a la construcción de la historiografía feminista, especialmente de la maternidad en un estado netamente patriarcal. Veronica puede crear una identidad alternativa para la nueva generación de mujeres, de independencia y auto-conciencia dentro de la sociedad irlandesa.

\section{La figlia scura/La hija oscura- Elena Ferrante}

La hija oscura es una nouvelle contada en primera persona desde el punto de vista de Leda, una profesora de literatura de cuarenta y siete años, divorciada, que veranea sola en la costa del mar Jónico. Desde la primera escena, el lector puede vislumbrar que la protagonista tiene tanto problemas físicos como emocionales:

Cominciai a sentirmi male dopo meno di un'ora di guida [...] La testa nel giro di pochi minuti mi diventó pesanti, i fari mi sembrarono sempre piú pallidi, presto dimenticai persino di essere alla guida [...] mi sono convinta che non si è trattato di un sogno, ma di una fantasia d'allarme durata fino al risveglio in corsia (Ferrante, 2006). ${ }^{21}$

19 El pasado no es un lugar feliz. Y el dolor del pasado es más de ella que mío. ¿Quién soy yo para atribuírmelo? Mi pobre madre ha tenido doce hijos (Enright, 2009: 703).

20 Quiero encontrar a la persona que hice con la materia de mi propio cuerpo [...] En definitiva, quiero acabar la tarea de hacerla para que, cuando esté acabada, sea fuerte. (Enright, 2009: 463). 
La sensación de desconexión de Leda consigo misma, su familia y todos los que la rodean la ha dejado sin anclaje. Es algo que ella todavía no ha conseguido entender y que prefiere no indagar.

Leda tiene dos hijas adultas que viven con su padre en Canadá. Antes de que las hijas se fueran, pensaba en la partida y anticipaba un periodo de abandono y soledad, sin embargo -sorpresivamente para ella- cuando ocurre, se siente liberada: "scoprii con imbarazzata meraviglia che non provavo alcun dolore, ma mi sentivo leggera come se solo allora le avessi definitivamente messe al mondo" (Ferrante, 2006). ${ }^{22}$

Leda siente que, por primera vez en muchos años, puede hacer lo que quiere "l'ansia di dover curare di loro" (ibíd.). ${ }^{23}$ También confiesa que la única obligación que ella siente para con sus hijas es "telefonare una volta al giorno per sapere come stavano,, cosa facevano". ${ }^{24}$ Desde el comienzo de la nouvelle, podemos observar que, para Leda, la maternidad es una práctica contingente más que una identidad. Siente que de alguna manera su tarea como madre está terminada y está conforme con eso: "Mi sentii miracolosamente svincolata, come un'opera difficile, giunta infine a compimento, non mi gravasse piú addosso" (ibíd) ${ }^{25}$

En la playa, los días de Leda se adaptan rápidamente a una rutina: nadar y trabajar a la sombra preparando sus clases para el próximo año. Unos días después de su llegada, ve a una joven y su hija. Leda está impresionada con la relación entre ambas, que parece simbiótica: "Si parlavano con calma, come se esistessero solo loro" (Ferrante, 2006). ${ }^{26}$

Leda observa con admiración cómo la joven y su pequeña juegan en el agua con la muñeca. Leda se convierte en la observadora obsesionada de las dos mientras trata de descifrar la estructura familiar, sus nombres y apodos: Nina, la madre; Elena, la hija; Nani, la muñeca. Más tarde, Leda descubre que la mujer y la niña que ella admira forman parte de un grupo familiar de napolitanos cuyo comportamiento le trae recuerdos no deseados del medio poco refinado en el que creció y del que escapó para vivir en la más respetable Florencia.

La fase contemplativa de Leda alcanza un punto crítico durante el primer fin de semana, cuando la playa se torna demasiado caótica para intentar preparar sus clases o leer, entonces, busca a la madre y a la niña a fin de pasar el rato. De repente, Leda está molesta, se da cuenta de que Nina anima un personaje para los que la están observando: "Sospettai che mettesse in scena il suo ruolo di madre

22 "...descubrí con inquieta sorpresa que no sufría ningún dolor, sino que me sentía ligera como si solo entonces las hubiera dado a luz definitivamente" (Ferrante, 2017: 395).

23 "sin tener el apremio de cuidar de ellas" (ibíd.)

24 " llamarlas una vez al día para saber cómo estaban, qué hacían" (ibíd.)

25 "Me sentí milagrosamente desvinculada, como si una obra difícil, llevada al fin a su término, hubiera dejado de ser una carga" (ibíd.)

26 "Se hablan con calma, como si no existiera nadie más que ellas dos" (Ferrante, 2017:403) 
giovane e bellissima non per amore della figlia ma per noi, la folla della spiaggia" (Ferrante, 2006). ${ }^{27}$

Al principio, Nina y Elena parecían ajenas y no contaminadas por su familia extendida, aunque esto último le recuerda a Leda a su propia madre, quien trataba de distinguirse, con elegancia y buen gusto, de la familia rústica de su marido.

Mia madre si vergognava della natura plebea di mio padre e dei parenti, voleva esseri diversa, giocava, dall'interno di quel mondo, a fare la signora ben vestita e di buoni sentimenti. (Ferrante, 2006) ${ }^{28}$

La acción de la novela se centra en Elena perdida en la playa. Al principio, Leda participa de la escena como espectadora, hasta que encuentra a Nina con "gli occhi mobilissimi erano pazzi d'ansia” (Ferrante, 2006) ${ }^{29}$. Leda recuerda a su madre quien solía decirle que, de chica, ella siempre se perdía; sin embargo, Leda "Temevo che fosse mia madre a perdersi, vivevo nell'ansia di non riuscire piú a trovarla”30 (Ferrante, 2006).

Este recuerdo le dispara otro: las pocas veces que había perdido a sus hijas en la playa y cómo ella miraba desesperadamente en todas direcciones para encontrarlas, menos hacia el mar, ya que no podía tolerar siquiera dirigir la mirada hacia allí. Al ver a Nina proceder de igual forma: "Frugava dovunque ma voleva disperatamente le spalle al mare" (ibíd.) ${ }^{31}$, Leda se conmueve y participa de la búsqueda de la niña. Mientras lo hace, se imagina poniéndose en el lugar de la hija perdida.

La bambina che si perde tra la folla sulla spiaggia vede ogni cosa immutata e tuttavia non riconosce piú niente. Le manca l'orientamento [...] La bambina si sente esattamente dov'era e tuttavia non sa dov'è [...] All'adulto sconosciuto che le chiede cosa c'è, perchè piange, non dice che si é persa, dice che non trova piú la mamma (Ferrante, 2006). ${ }^{32}$

Esta forma de empatizar con Elena, poniéndose en su lugar, es una proyección y Leda lo reconoce como tal. Una criatura perdida no llora porque está perdida sino porque no puede encontrar a su madre. Cuando Leda finalmente encuentra a Elena, la niña le dice que llora porque "aveva perso la bambola" (Ferrante,

27 "Sospeché que estaba representando su papel de madre joven y bella no por amor a la hija sino para nosotros, la gente de la playa" (Ferrante, 2017: 408)

$28 \mathrm{Mi}$ madre se avergonzaba de la naturaleza plebeya de mi padre y sus parientes, quería ser distinta jugaba dentro de aquel mundo a ser la señora bien vestida y de buenos sentimientos (Ferrante, 2017: 412).

29 "enloquecida de ansiedad" (Ferrante, 2017: 429)

30 [T]emía que fuera mi madre la que se extraviara, vivía con la angustia de no volver a encontrarla" (ibíd.)

31 "[B]uscaba por todas partes pero daba la espalda al mar de un modo desesperado" (ibíd.)

32 La niña que se pierde entre la multitud de la playa no aprecia ningún cambio en las cosas y sin embargo ya no reconoce nada. Le falta orientación, [...] La niña cree estar exactamente donde estaba antes y sin embargo no sabe dónde está ahora. [...] Al adulto desconocido que le pregunta qué pasa, por qué llora, no le dice que se ha perdido, le dice que no encuentra a su mamá (Ferrante, 2017: 430). 
2006). ${ }^{33}$ La niña está buscando algo determinante, no está perdida sino frustrada y triste. Leda proyecta su estado de ánimo en Elena cuando sale a buscarla, una encarnación literal de su estado de ansiedad: Leda está perdida en sí misma.

Leda también es una hija perdida (como Elena, su hija y ella misma) y una madre (como Nina, ella misma y su madre) que ha perdido una hija. A través de Nina, Leda ocupa roles de madre e hija simultáneamente y se pregunta por la (in)capacidad de mothering tanto de ella misma, como de su madre y de Nina.

El robo de la muñeca por parte de Leda no se hace presente para el lector, Leda misma parece no poder recordarlo: "Scoprii che non riuscivo a ricordare il momento preciso di un'azione che ora giudicavo quasi buffa, buffa perché priva di senso" (Ferrante, 2006) ${ }^{34}$. Pareciera que este hecho más bien resulta ser una manera de relacionarse con Nina como madre. Nani, la muñeca, funciona en este caso como símbolo de la conexión entre madre e hija.

Podemos inferir que la relación perfecta entre Nina y Elena es lo que la lleva a robar la muñeca ya que es el testimonio de esa maternidad, algo que Leda envidia. El robo de la muñeca afecta inmediatamente a Elena, si bien la víctima real es Nina quien no puede hacer feliz a Elena, y de esta manera su mothering se lleva al límite: "Sentii che stava oscillando tra pazienza e insofferenza, comprensione e voglia di mettersi a piangere. Dov'era l'idillio a cui avevo assistito in spiaggia." $\left(\right.$ Ferrante, 2006) ${ }^{35}$. El robo de la muñeca hace que Nina sea más parecida a Leda como madre y a la madre de Leda, asfixiada y bajo presión, uniendo de este modo las tres concepciones de mothering.

Leda, al igual que Veronica en The Gathering, lucha contra "el crimen cultural" de querer contrariar el modelo patriarcal de la maternidad; pone su carrera como académica y a ella misma y sus deseos primero, una de las razones principales por las que deja a su marido y sus hijas. Cuando Leda habla de sus hijas, se expresa con celos, disgusto, resentimiento y exasperación. Cuando Leda le confiesa a Nina haberse alejado de sus hijas, lo hace sin emoción: "Me ne sono andata. Le ho abbandonate quando la piú grande aveva sei anni e la seconda quattro [...] Certe volte scappare serve a non morire" (Ferrante, 2006) ${ }^{36}$. Leda pone todo en términos de deseo, hasta la decisión de regresar a sus hijas, otra vez, por ella misma. En una conversación, Nina le pregunta si había vuelto por amor a sus hijas, Leda le contesta: “No, sono tornata per lo stesso motivo per cui me n'ero andata: per amor mio [...] mi sono sentita piú inutile e disperata senza di loro che con loro" (Ferrante, 2006) ${ }^{37}$.

33 "había perdido a su muñeca" (Ferrante, 2017: 430)

34 "Me di cuenta de que no conseguía recordar el momento preciso de una acción que ahora juzgaba ridícula, ridícula por su falta de sentido" (Ferrante, 2017: 433).

35 "oscilaba entre la paciencia y el hartazgo, entre la comprensión y las ganas de llorar. Poco quedaba del idilio al que había asistido en la playa" (Ferrante, 2017: 454)

36 "Me fui. Las abandoné cuando la mayor tenía seis años y la pequeña cuatro [...] En ocasiones hay que huir para no morir" (Ferrante, 2017: 456).

37 "No, volví por el mismo motivo por el que me había ido: por amor a mí misma [...] me sentía más inútil y desesperada sin ellas que con ellas" (Ferrante, 2017: 507). 
Ni el abandono ni el regreso resultan ser un sacrificio para Leda: es culpable de no sentirse culpable. Leda se rehúsa a idealizar la maternidad mediante la retórica del sacrificio. Por ejemplo, cuando Leda habla de embarazo, lo narra como un sacrificio personal necesario:

la carne pulsa di una vita rotonda che è tua, la tua vita, e però spinge altrove, si distrae da te pur abitandoti la pancia, gioiosa e pesante, goduta come un impulso vorace e tuttavia repellente [...] La tua vita vuole diventare di un altro $\left(\right.$ Ferrante, 2006) ${ }^{38}$.

Leda describe la psicología emocional y el sentido somático de eliminación que se siente al ser madre. La vida de Leda con sus hijas o sin ellas está constituida por la pérdida de ella misma. En los tres años de ausencia, Leda experimenta "una mancanza insopportabile" (Ferrante, 2006) ${ }^{39}$ y a su vuelta se resigna a vivir "poco per me e molto per le due bambine" (Ferrante, 2006) ${ }^{40}$. Así, la subjetividad maternal está continuamente marcada por el sentido de pérdida, especialmente sobre el control de sí misma. La novela no idealiza la maternidad ni se encuadra en la ideología del sacrificio maternal, aun cuando la maternidad esté descrita como sacrificada.

La hija oscura describe el concepto de mothering recurriendo a la imagen de una cadena (especialmente del linaje femenino de la familia) que Leda trata de romper.

Le speranze della giovinezza parevano già tutte bruciate, mi sembrava di precipitare all'indietro verso mia madre, mia nonna, la catena di donne mute $o$ stizzose da cui derivavo (Ferrante, 2006). ${ }^{41}$

Esta "reacción en cadena" crea madres infelices que trasladan su ira a los hijos. Al igual que Veronica, Leda relaciona a su madre, su abuela y la "cadena de mujeres mudas o coléricas de las que descendía" con su propia furia y resentimiento y siente la necesidad de no convertirse en una más de esas mujeres. Este deseo de escaparse del destino familiar se extiende también a las hijas. Cuando Bianca y Marta, sus hijas, tenían problemas en la escuela, Leda usaba a su madre y a su abuela como ejemplos negativos:

che volete combinare nella vita, dove volete finir, volete tornare indietro, degradarvi, abolite tutti gli sforzi che abbiamo fatto vostro padre e io, tornare a com'è vostra nonna, che ha solo la licenza elementare (Ferrante, 2006). ${ }^{42}$

38 la carne palpita con una vida redonda que es tuya, tu vida, y sin embargo empuja hacia otra parte, se separa de ti a pesar de habitar en tus entrañas, feliz y pesada, gozada como un impulso voraz y aun así repulsivo [...] Tu vida quiere ser de otro (Ferrante, 2017: 425)

39 "un vacío insoportable" (Ferrante, 2017: 507).

40 "poco para mí y mucho para las niñas" (Ferrante, 2017: 508).

41 "Las esperanzas de la juventud parecían haberse esfumado, tenía la sensación de que me precipitaba hacia atrás, hacia mi madre, mi abuela, la cadena de las mujeres mudas o coléricas de las que descendía" (Ferrante, 2017: 460).

42 "qué queréis hacer con vuestra vida, cómo vais a acabar, vais a volver atrás, degradaros, dar al traste con 
El mayor miedo de Leda cuando abandonó a sus hijas era que su marido las dejara con su madre y que las niñas tomaran costumbres y características de sus ancestros.

Le due bambine sarebbero sprofondate piano piano nel pozzo nero da cui venivo, respirandone i modi, la lingua, tutti i tratti che mi ero cancellata di dosso quanto ero andata via dalla città a diciotto anni $\left(\right.$ Ferrante, 2006) ${ }^{43}$

Los dos alejamientos (de su madre y de sus hijas) de Leda se funden, ya que al hablar de uno inevitablemente se piensa en el otro, de esta manera sugiriendo que los dos están relacionados. Dejar a las hijas es otra forma de romper con la cadena del mandato maternal. Al finalizar la novela, Leda confiesa el robo de la muñeca a una incrédula Nina con una lacónica y sórdida explicación: “Sono una madre snaturata"(Ferrante, 2006) ${ }^{44}$.

Mucho se ha hablado de la maternidad en los últimos años, si bien a la literatura escrita por mujeres, especialmente, todavía le resta un largo camino por recorrer en el análisis, la redefinición y la búsqueda de nuevas ontologías de la maternidad. De una manera significativa se observa que, en la literatura contemporánea escrita por mujeres, la maternidad y su problemática juegan un rol destacado. Representar la maternidad en la literatura supone proyectar las percepciones y las actitudes femeninas ante la realidad, apartando los códigos literarios androcéntricos a fin de dar mayor visibilidad a la mujer. Las obras de Anne Enright y Elena Ferrante encierran un desafío al concepto de maternidad impuesto por la sociedad patriarcal. Ambas artistas oponen la madre real con la idealizada y, al hacerlo, deconstruyen la imagen de la maternidad. Tanto Leda como Veronica quieren romper el estereotipo patriarcal de la madre, la maternidad y mothering. La violencia, la muerte y el abandono se anticipan a esa lucha, ambas parecen haber ganado la batalla, pero ¿a qué precio? La maternidad como crianza y cuidado, mothering como principio y práctica, se adaptan y evolucionan a lo largo de la historia de la humanidad y dan esperanzas de continuidad.

La representación de la femineidad en las novelas analizadas resulta provocadora e innovadora a la vez; hace audible la voz materna largo tiempo censurada y silenciada y al mismo tiempo pone en tensión los conceptos de lo femenino y la maternidad. De esta forma logra encontrar una nueva manera de resignificarlos dentro de un momento discursivo renovado en la literatura del siglo veintiuno.

todos los esfuerzos que hemos hecho vuestro padre y yo, ser como vuestra abuela, que solo tiene el certificado de estudios primarios" (Ferrante, 2017: 478).

43 Las niñas hubieran caído poco a poco en el pozo negro del que provenía, absorbiendo sus costumbres, la lengua, todos los rasgos que me había quitado de encima cuando me fui de la ciudad a los dieciocho años (Ferrante, 2017: 477).

44 "Soy una madre desnaturalizada" (Ferrante, 2017: 530)." 


\section{Bibliografía}

"Benedetti, L. (2007). Tigress in the Snow: Motherhood and Literature in 20th-Century Toronto: University of Toronto Press.

" Bock, G. y Thane, P. (eds.) (1996). Maternidad y políticas de género: la mujer en los estados de bienestar europeos, 1880-1950; traducción de Jerónima García Bonafé. Madrid: Cátedra.

"Brogan, P. (2004). The Magdalene Experience. Motherhood in Ireland: Creation and Context. Cork: Mercier Press.

"Butler, J. (1993). Bodies that Matter. On the Discursive Limits of "Sex". New York: Routledge.

"Butler, J. (2016). El género en disputa. El feminismo y la subversión de la identidad. Buenos Aires: Paidós.

"Constitution of Ireland .Constitution of Ireland/ Bunreacht na hÉireann, December 2013, http://www.irishstatutebook.ie/ (consulta: 1/2/2019).

"Di Stefano, P. (20 noviembre 2011). "Ferrante: felice di non esserci" Corriere della Sera. Recuperado de http://lettura.corriere.it/news/ferrante-felice-di-non-esserci/ (consulta: 1/2/2019).

"Domínguez, N. (2007). De dónde vienen los niños. Maternidad y escritura en la cultura argentina. Rosario: Beatriz Viterbo.

"Enright, A. (2007). The Gathering. Londres: Vintage.

" Enright, A. (2009). El encuentro. Barcelona: Lumen.

"Ferrante, E. (2006). La figlia scura. Roma: E/O Edizioni.

"Ferrante, E. (2017). La hija oscura. En Crónicas del desamor. Buenos Aires: Penguin Random House.

"Hansen, E. (1997). Mother without Child. Contemporary Fiction and the Crisis of Motherhood. Los Angeles: University of California Press.

"Jeremiah, E. (2006). "Motherhood to Mothering and Beyond: Maternity in Recent Feminist Thought." Journal of the Association for Research on Mothering, 8 (1/2). pp. 21-33.

" Kristeva, J. (1975). "Motherhood according to Bellini" En Oliver, K. (ed.) (1997) Portable Kristeva (pp. 301-308). Nueva York: Columbia University Press.

" Kristeva, J. (1976). "Stabat Mater". En: Oliver, K. (ed.) (1997) Portable Kristeva (pp. 308331). Nueva York: Columbia University Press.

"Meaney, G. (2010). Gender, Ireland and cultural change: race, sex and nation. Nueva York: Routledge.

"Podnieks, E. y O'Reilly, A. (eds.) (2010). Textual Mothers/Maternal Texts Motherhood in Contemporary Women's Literatures. Ontario, Canada: Wilfrid Laurier University Press.

"Rich, A. (1986). Of Woman Born: Motherhood as Experience and Institution. Nueva York: W.W. Norton \& Co.

"Russo B. y Love, S. (eds.) (2016). The Works of Elena Ferrante. Reconfiguring the margins. Nueva York: Palgrave Macmillan. 
La maternidad en conflicto en The Gathering...

"Sydora, L. (2013). "Feminizing Ireland": Cultural Revisionism and Feminist Writing in Celtic Tiger Ireland. Edmonton: Alberta.

" Toril, M. (1988). Teoría literaria feminista. Madrid: Ediciones Cátedra. 